\title{
The spectre of the wheezy dad: Masculinity, fatherhood and ageing
}

Fiona Shirani, Cardiff University, School of Social Sciences, UK

\section{Accepted for publication in Sociology}

\section{Corresponding author details:}

Fiona Shirani, Cardiff University School of Social Sciences, Glamorgan Building, King Edward VII Avenue, Cardiff, CF10 3WT, UK.

Email: fionashirani@cardiff.ac.uk

\section{$\underline{\text { Abstract }}$}

This paper explores concerns about and experiences of ageing amongst men during the early years of fatherhood. Despite acknowledgement of the interconnectivities between age and gender, accounts of ageing masculinity have been relatively overlooked, particularly in relation to younger and middle-aged men's perceptions of ageing. However, some evidence suggests that despite a general trend towards increasing longevity, anxiety about ageing is occurring at ever younger ages. Drawing on data from a qualitative longitudinal study, this issue is considered here through a parenting lens in light of the wider social trend towards delayed fatherhood. The paper focuses on the experiences of men aged 29-54 whose accounts indicate widespread concern about ageing, regardless of their actual chronological age. The analysis foregrounds how these concerns are linked to the continuing association between fathering and physical activity, which highlights the need to consider the implications of advanced paternal age for father-child relationships.

Key words: Ageing, Body, Fatherhood, Masculinity, Physical activity 


\section{$\underline{\text { Introduction }}$}

Individualisation theorists have questioned the continuing influence of chronological age, arguing that age identities become increasingly fragmented in a period of late modernity (Vickerstaff, 2006; Mac an Ghaill and Haywood, 2007). However, others have demonstrated the continuing salience of chronological age for judging the timeliness of events (Elchardus and Smits, 2006), indicating that, rather than withering away, age remains an extraordinarily powerful concept (Brannen, 2002). In fact, despite a trend towards increased longevity, some point to the way in which anxiety about advancing chronological age appears to be increasing, occurring at ever younger ages, which Jagger (2005:103) attributes to a consumer culture 'tyranny of youth'. Despite this apparent paradox of ageing anxiety alongside increasing longevity, there has been little research considering younger and middle-aged people's perceptions of ageing, and the limited existing data on this topic are predominantly quantitative. For example, in survey research exploring undergraduate students' perceptions of older people, Thompson (2006) found an emphasis on how ageing diminishes a man's sexual, physical and psychological capabilities, and how men are believed to lose agency with age. Similarly, Hummert et al. (1994) found that middle aged participants (defined as 35-51) most frequently described the elderly as health-conscious and scared of becoming sick or incompetent, suggesting an equation of old age with limited physical abilities. Despite contentions that chronological age may not equate with subjective age or health (Bytheway, 2005), existing research evidence suggests these parallels are drawn by younger people envisaging a problematic relationship between age and masculinity in later life. This is perhaps unsurprising given negative cultural perceptions of older age as linked to limited physical abilities and biological failure (Hummert et al., 1994; Gulette, 1997). Consequently, the internalisation of these negative images may increase personal anxiety about ageing 
(Hepworth, 1995). It may be that anxiety is occurring at earlier ages as this time is identified as an opportunity for effective intervention, passing responsibility to the individual to remain 'forever functional' (Marshall and Katz, 2002). Subsequently, it is important to consider the expectations and anxieties around ageing held by younger groups.

The interconnectivities between age and gender have received relatively little attention in the research literature in relation to the masculinities of older men (Arber et al., 2003). However, the social processes of gender include ageing (Connell, 2005), meaning that the interplay between age and gender generates specific meanings about masculinity and femininity (Mac an Ghaill and Haywood, 2007). The once privileged position of older men valued as experienced and powerful is arguably no longer tenable given contemporary focus on the body (Hearn, 1995). Consequently, some have contended that the 'double standard of ageing' where age is valued in men but seen as a disadvantage for women, is becoming fragmented (Gulette, 1997). It is argued that changes in ability over time may mean that growing older is experienced by some men as entering 'marginalised manhood' in relation to hegemonic masculinity, which is based on the lives and bodies of younger men (Comeau and Kemp, 2007). Subsequently, this inverse correlation between masculinity and ageing (SpectorMersel, 2006) may represent challenges to identity in later life.

It has been observed that men's embodied experiences have been overlooked (Fleming, 1999), yet as true masculinity is almost always thought to proceed from men's bodies meaning the physical sense of maleness is central to the cultural interpretation of gender - the importance of men's bodily experience needs to be accounted for (Henwood et al. 2002; Connell, 2005). Whilst the literature on men's experiences as embodied, ageing subjects has been limited, exploration of these issues has been particularly sparse in relation to fatherhood. 
One notable exception is the work of Doucet (2006), who has documented the ways in which fathers call the body into use in articulating their experiences as strong, physical and active beings. Doucet found that fathers emphasised their involvement in play and sport with their children, particularly sons, which lends support to research documenting the way in which fathers' involvement with children has been characterised by a high level of activity (Parke, 1996; Lamb, 2010). Given this association, it would appear important to explore men's expectations of age-related bodily changes in relation to fatherhood. In addition, the documented trend towards delayed fatherhood foregrounds the need to consider the implications of advanced paternal age for father-child relationships in light of this emphasis on activity. There has been little research on children's perceptions of older fathers; although in the student survey cited above, Thompson (2006) found that respondents who had older fathers were less likely to evaluate older men in instrumental or masculine terms, which suggests father age has implications for both men's own sense of masculinity and their children's perceptions of this. Rather than focus exclusively on older fathers, this paper considers the experiences of men across different age groups to highlight how pervasive ageing anxiety can be.

This paper's focus on physical activity reflects the connection between ageing and embodiment. However, this is not to suggest that other aspects of fatherhood do not also contribute to masculine identity. For example, research continues to explore the relationship between masculinity and economic provision (Henwood et al., 2010), a form of fathering masculinity which shows continuity across generations. Alternatively, expectations of men's increasing involvement in the practical care and emotional work of family life can be seen to offer new opportunities for the transformation of masculinity (see Shirani et al., 2012 for further discussion). However, this paper predominantly attempts to fill some of the existing 
gaps in the literature by exploring the accounts of young and middle-aged men as they reflect on their experiences and sense of ageing and activity in relation to fatherhood and masculine identity. Rather than focus solely on older fathers, the analysis draws on experiences of ageing anxiety from men in different age groups, highlighting the prevalence of these concerns across the sample.

\section{Study Design}

This paper draws on data collected for Men as Fathers Study led by Professor Karen Henwood at Cardiff University, part of the qualitative longitudinal Timescapes network, and my linked $\mathrm{PhD}$ study into the 'right time' for fatherhood. Participants were recruited during their partner's pregnancy and interviewed once before the birth of their child and up to twice in the first year afterwards. The sample consists of four groups:

- A - 19 men who became fathers for the first time in 2000 (in East Anglia). Also interviewed once in 2008. (Aged 26-41)

- B - 11 men who became fathers for the first time in 2000 (in East Anglia). Could not be traced in 2008. (Aged 20-36)

- C - 15 men who became fathers for the first time in 2008 (in South Wales). (Aged 15-40)

- D - 8 men interviewed once in 2008/9 during the first 12 months of first-time fatherhood (in South Wales and South West England). These men were specifically sampled for $\mathrm{PhD}$ research based on their age at the transition to fatherhood (under 22 or over 40)

In total, this creates a sample of 53 men aged 15-54 at the time of their child's birth. Participants were employed in a wide variety of occupations, with the majority working fulltime $(n=43)$ whilst a small number worked part-time $(n=4)$, were students $(n=4)$, or were unemployed $(n=2) .50$ participants were married or cohabiting, whilst three were living apart 
or separated from the child's motheri. I conducted most interviews with sample C and D participants, whilst samples A and B were predominantly interviewed by other researchers. The impact of research team changes is an important issue for longitudinal research, a topic I have discussed in depth elsewhere (Shirani, 2010).

Exploring the issue of ageing and the importance of physical activity to father identity was not part of the initial research design, yet was a topic raised in the accounts of many men, to an unanticipated extent. The topic emerged as important in my $\mathrm{PhD}$ research on the 'right time' for fatherhood as numerous men across the sample reflected on the importance of being able to be physically active as a father throughout their offspring's childhood and adolescence, with the potential inability to do this forming the main concern about delaying fatherhood. Subsequently the data presented in this paper emerged as the men reflected on fatherhood rather than in response to a particular question. Whilst concerns about ageing were raised particularly strongly by the oldest fathers, it appears that many of these anxieties were felt by men across the sample from their late 20s onwards. The paper therefore does not focus only on those who have delayed conception but considers the prevalence of these concerns across the sample to highlight this as an issue for men of different ages. The subsequent implications this has for older fathers in particular, however, are drawn out in the conclusion.

Men as Fathers project work has previously delineated the benefits of using qualitative longitudinal (QLL) methods for studying fatherhood rather than a one-off 'snapshot' approach (Shirani and Henwood, 2011). Lewis (2007) describes QLL as research which seeks to explore change over time through more than one episode of data collection, thus emphasising temporality. Indeed it is this focus on time, particularly the interplay of the 
temporal, personal and cultural through focus on time and texture, which makes QLL unique. Whilst participants were not asked specifically about ageing, it may be that the inherently temporal nature of this research prompted reflections on change - particularly for those where the gap between interviews had been several years - meaning the topic of ageing became more prominent than it may otherwise have done in a one-off interview context. Whilst a qualitative longitudinal study provides opportunities to analyse data over time (diachronically) using a case study approach, analysis can also be undertaken at one point in time (synchronically) across a wave of interviews with different participants (Elliott et al., 2008). Rather than adopt a case study approach focussed on particular individuals, this paper presents data from a range of men in order to demonstrate the prevalence of talk about ageing and fatherhood across the sample and amongst different age groups. The analysis begins by situating the men's experiences in relation to existing literature on 'bodies that do' before exploring the significance of chronological age markers to perceptions of self-ageing. Men's talk about ageing and embodiment in relation to fatherhood is then considered, reflecting on the implications that this has for timing decisions.

\section{Bodies that 'do'}

Previous research has highlighted the gender-differentiated ways in which men and women talk about their bodies, with varying emphasis on functioning and ability. In a study by Halliwell and Dittmar (2003) exploring men and women's relationship to their bodies, the importance of the body because of what it allows the person to do was found in $100 \%$ of the men's accounts, suggesting that physical functioning is a particularly important issue for men. One way in which physical abilities can be demonstrated and worked on is through sport, with men often participating in competitive physical activities with friends and with sons as they got older. This links in to abstract notions about masculinity as something 
achieved through bodily performance (Connell, 2005). Although historically sport has institutionalised the values necessary for manhood; competitiveness, toughness and a desire to win (Robertson, 2003), sports encounters may prove particularly problematic in terms of ageing as they enlarge generation gaps, generating inferiority in older men (Gulette, 1997) by creating 'veterans' in their thirties (Comeau and Kemp, 2007). For example, at 29 years old Ashley described being seen as 'bloody ancient' by the younger players in his weekend football team, whilst at 40 Jason's football activity also contributed to his sense of ageing.

I play veterans football ... Football for the over 35s, (general laughter) ... I think psychologically that is where I'm thinking, “I'm getting old, I'm getting old" maybe I am underneath that starting to panic about life going by ... And obviously when you look at it and the next thing is like as you get older, there's more chance of things going wrong ... your health and stuff like that. (Jason, 40, A, children aged 8 and 5)

Hearn (1995) suggests that men are particularly concerned about physical breakdown because it connects the masculine body with weakness, dependency and passivity, therefore highlighting how age has become a new source of risk to men and their masculinity. Some men commented on how being able 'to do' had become harder with age, as Howard indicates.

I just think it's harder now because I'm older and I ache more, I feel less physically able. 'cause I like, when I was sort of at my peak, I'm quite a practical sort of person, I like sort of repairing things and doing DIY and things ... I still do quite like doing it but I find it harder to do and hence I get more stressed, I get sort of hotter doing it and more stressed you know, 
more expletives come out through things that aren't going how I want them to go at the time. It's not good really but I have to do something and that is pretty much all I can do that is useful. (Howard, 44, A, child aged 8)

Howard was unemployed and spent much of his time doing DIY around the house. When this became more difficult, due to what he perceived to be age-related physical decline, it undermined the sense of usefulness he derived from undertaking these tasks and therefore had implications for his sense of identity.

In early post-birth interviews, several men expressed concerns that the demands of a young baby had reduced their time for exercise, which, combined with an increased reliance on convenience food, led to some anxieties about letting oneself go.

I mean there is no doubt that I have put a bit of weight on since he was born ... because I have got other things to think about, but it is also something that I am not content to let go ... I am not going to allow myself to get progressively fatter, and therefore I will have to do something about it ... I feel worse when I am heavier than when I am not. And also my job takes me off doing peculiar things in Land Rovers on bumpy roads ... you just have to be fit to rough it slightly, so all of that sort of feeds in. I don't think really that being a father and possibly a sort of Greek God role model for example for my son is not really part of that. But I mean also yes I suppose what follows from the rest of it is that I don't want to be a couch potato, I want to be able to run around and do stuff with him when he is old enough to do it. (Simon, 35, A, child aged 1) 
Here Simon's dissatisfaction with weight gain and declining fitness levels is linked to his desire to remain able to do things both for his job and with his son. However he is clear to emphasise that he is not concerned with appearance in being a 'Greek god' but functionality in 'being able to run around and do stuff'. In this way he clearly indicates his concerns are related to fitness rather than appearance, distancing himself from perceptions of vanity or obsession (Gill et al, 2005).

Despite the focus on bodies 'that do', several men commented on concerns about being or becoming fat. In addition to physical functioning, external appearance is considered a reflection of the self, symbolising social status; therefore people whose body does not comply with the ideal rank lower in the hierarchy (Spector-Mersel, 2006). Fatness has threatening implications for men given the way it potentially undermines normative forms of masculinity, representing lack of firmness and self-control (Bell and McNaughton, 2007) the ultimate form of letting oneself go (Gill et al., 2005). Malcolm describes his decision to lose weight as motivated by a desire to give a good impression at work, indicating that the fatness is not associated with who he 'really' is. This suggests an interior self that does not mature at odds with a body defined as disagreeable (Gulette, 1997).

I don't like being fat, not that I'm humongously fat but I'm carrying a bit of weight round my tummy ... I don't like it, I don't think it creates a good image at work, don't think it portrays me as the person probably that I really am. I don't know why, I think there's a lot of negativeness about being overweight ... If I think back about my father he carried weight and I used to be quite embarrassed about it ... so I think perhaps my kids do as 
well, it's not good, it's important what they think. (Malcolm, 40, A, children aged 8 and 5, teenage stepson)

Malcolm's dissatisfaction with and motivation to change his weight are linked to memories of his own father and concerns that his children may view him in a similarly negative way (see Coltart and Henwood 2012 for further discussion). Being well thought of by their children was important for all the men and was often a prompt for engaging in physical activities with them. In this way being able 'to do' was an important part of how they defined the father role.

\section{Fear of Forty}

Throughout the interviews, chronological age proved an important lens through which men articulated their experiences, with particular concerns expressed about getting older. Revisiting sample A participants eight years after the birth of their first child, the majority had experienced turning forty as a significant point in their lives. In discussing 'fear of fifty', Gulette (1997) suggests that these significant changes in age make visible and collective what might be evanescent moments of panic, reflecting changes in future expectancy. This is particularly salient given the pervasiveness of lifespan time for evaluating our lives, interpreting our past and planning our futures (Spector-Mersel, 2006). For example, men described anxieties about turning forty as this marked a different conception of past and future; perceiving that there was less ahead than there was behind (Hamand, 1994). This may include reflections on the gap between early aspirations and present accomplishments, which alongside biological changes can represent a particular source of stress (Eisler and Ragdale, 1992). Jason reflects some of these concerns in his account of dissatisfaction with turning 
forty - described as 'a massive turning point' - which he relates to shifting perceptions of past and future.

I turned into a miserable old man on that day ... I felt like I had my big celebrations at 21 where you're like ... it sounds wrong when you say you've got a lot more to look forward to, I think that's just, your expectation is, when you're 21 compared to maybe what your expectation is when you're 40 is slightly different ... I think where your future is, where you're looking outside massively, massive wide world there at 21 where, probably my ambition is not, I wouldn't say is not so high, but is different ... obviously I've still got a life, but it's very different to where I was when I was 21. (Jason, 40, A, children aged 8 and 5)

As midlife is often associated with losses in beauty, health, sexuality, parenting and earning power, ageing-as-inward-anxiety has arguably become a quintessential midlife problem (Gulette, 1997). This may be because midlife is seen as an opportunity for effective intervention (Marshall and Katz, 2002). For example, men have reported efforts to take care of their bodies and satisfaction about doing this in terms of combating the body decline (Wandel and Roos, 2002). The popular notion that one should 'age successfully' requires the maintenance of activity and resistance to culturally designated markers of old age (Calasanti and King, 2005). At forty, Keith described embarking on a recent health and fitness plan as one of his most significant life events.

I sort of weighed myself and I was ... quite overweight and the wife was saying "you really should do something about it". So we went on a diet 
together and I lost about $3 \frac{1}{2}$ stone ... that was quite life changing, yeah 'cause I've become a lot fitter so I thought I don't wanna go back so I was throwing all the fat trousers out, new wardrobe, exercising more, running you know, keeping fit ... I'm not sure how it fits in to fatherhood but um maybe that midlife crisis or something so, no I haven't been this weight since I was 16 (laughs) (Keith, 40, A, children aged 8 and 5)

Keith jokes that the weight loss was part of his 'midlife crisis', which enabled him to return to his teenage weight, suggesting that despite advancing chronological age he is able to reclaim some connections to youthfulness.

With those in sample $\mathrm{C}$ who became fathers most recently, concerns about ageing were articulated even earlier. For example, Neil described how turning thirty raised concerns about declining physical fitness, whilst, in a similar vein, William describes his experience of time passing quickly and his feelings of anxiety about becoming 'an old man' at the age of thirty one.

I'm 31, that's just the wrong side of 30, that's just not right. You see people on TV who you imagine to be older that you and you'll find out they're 27/28 and I think God what's happened to me? I'm an old man. There's nothing to look forward to age-wise; you celebrate your $18^{\text {th }}$, your $21^{\text {st }}$, maybe your $25^{\text {th }}$, certainly your $30^{\text {th }}$. But then you're $31 / 32$ so it's nothing till you get to 40 ; who wants to celebrate 40 ? Nobody. So yeah time does seem to rock on by now, you suddenly find you're in middle age and think 
where the hell did that go? How did that happen to me? How have I become a middle-aged man? (William, 31, C, child aged 1)

William's description of himself as 'middle-aged' at thirty one and his concerns about reaching forty are indicative of the way in which participants appeared to hold negative perceptions of what it means to be a middle-aged or older man and their concerns about the impact of ageing. Much of this sense of ageing appeared to come from lifestyle rather than physical changes. For example, William described a more restricted social life after the birth of his daughter where he no longer had the opportunity to keep up to date with the latest music through attending gigs, or socialising in the pub with friends. Like William, Ashley articulated concerns about ageing when still in his thirties.

I don't know whether it's a getting near 40 thing but we've both said this... you suddenly think bloody hell where's that gone? ... I think back to when my dad was 40 and I used to think that was bloody ancient and that bothers me a little bit ... I think to myself Christ that seems really old. (Ashley, 38, A, children aged 8 and 5)

Here Ashley relates his concerns about nearing forty to memories of his own father; an important factor in age experience which appeared to motivate men's decisions about the timing of parenthood.

\section{Father figures}

During their partner's pregnancy, participants were asked to reflect on the timing of fatherhood and what constituted right time, responses which were followed up in later 
interviews. Initially, being relatively fit was important to the majority of men across the sample, as being active with their children was perceived to be a central aspect of fatherhood. Physical abilities were therefore frequently drawn upon to justify timing decisions, as illustrated by Vincent.

If you are fit and healthy and able to run round and do things, then obviously it means you can participate a lot more with the child, which is I think good for both points of view ... I don't want to be a very old father because I still want to win at sports day in the father's race (amusement). (Vincent, 30, A, pre-birth)

Eight years later his continuing ability to be active with his children - and being able to demonstrate this in competition with other men - is one of the main ways Vincent explains the timing of his transition to fatherhood as right.

I'll still win the fathers race on sports day when they're teenagers, if they have fathers days at sports days any more ... I still do quite well at the fathers race at the moment, I wasn't that old a father ... I go out to win, and I often do win 'cause I'm tall and strong and fit ... Some of the really old dads they struggle, they wheeze after the thirty yard dash and that sort of thing (laughs). So it's fairly important. (Vincent, 38, A, children aged 8 and 6)

The importance of physical fitness was raised in early interviews but had become a much more pressing issue eight years later. This is likely to be related to a number of factors, such 
as; participants' advancing age, children's greater levels of activity, and the ill health or death of their own parents resulting in some men becoming members of the oldest generation in their family.

As both Malcolm and Ashley's accounts presented earlier in the paper have illustrated, men's perceptions of the importance of activity to the father role appeared linked to memories of their own fathers. Some men reflected on perceptions of their fathers as having been old when they were growing up, which impacted upon their own timing decisions. For example, Gary felt his older father was 'a bit out of touch' when he was growing up, which he found 'frustrating' and felt this limited the closeness between them. Gary hoped to avoid this with his own son by becoming a father at a younger age. Similarly, Carl became a father age 32; the same age his own father had been. This caused some concerns about his ability to be active with his child given memories of his own father's tiredness.

I'm going to be 39, when he's 7, I'm going to be 39 say, or 40, and I don't want to be one of these, knackered old sweaty dads, puffing and panting around the park, you know. Another thing, it goes back to perhaps, just the distance between me and my dad, I don't want that between the two of us ... I remember, like, my dad sitting on his chair, watching the telly and falling asleep because he was so tired, and when I was born, he would've been round about my age now, he would have been about 32/33 when I was born, so that I was, he was 40 and I was 7, full of energy, wanting to do lots of things, he was crashed out on the chair. (Carl, 32, A, pre-birth) 
These concerns about repeating their fathers' behaviour were not widespread as most of the men had embarked on parenthood at a later age than their own fathers. However it is possible that these anxieties may become more prevalent for future generations given the current trend towards delayed fatherhood (ONS, 2009).

Concerns about being perceived as old or elderly, mainly by their own children, were particularly pronounced amongst the oldest men in the sample. In addition to anxieties about longevity, these fathers worried about their advanced age and declining 'stamina to be a father':

I get rather tired in the afternoon after lunch at work, very difficult to stay awake if I've lost sleep. ... so there's that, I mean just sheer stamina to be a father. Clearly later on I mean I will be older, he will want to do more things, more active things, so it's running round and so on, perhaps I don't want to run around. As you get older things can happen; legs break, they don't repair properly, you get problems. It can happen at any age but it tends to happen later on. Um so there are reasons that way it could be a disadvantage to be an older parent, older father. (Lawrence, 54, D, child aged 3 months)

Others were anxious that their children may be subject to teasing because of advanced paternal age (Hamand, 1994).

I do have this fear of being the oldest dad at parents evening ... It's my biggest fear actually; turning up and being ten years older than all the 
other dads... I don't want my child ridiculed 'cause he's got an old dad, that's my fear. (Graham, 41, D, child aged 3 months)

In light of these concerns, older fathers made efforts to maintain physical ability and appearance, contrasting themselves with older fathers of previous generations. During his interview, Guy described his childhood perception of his own father as elderly and out-ofdate. Being older than his own father when becoming a parent had caused Guy some anxiety, although he alleviates this by emphasising how he appears and behaves much younger than his own father did at the same age.

I always thought of him as an elderly father because he was 41 when he had me but I was fourth so he was actually probably only about 33 when he first became a father, but in those days it was fairly old, 41 in those days was fairly old. Yeah it's quite funny (laughs) I was aware of that when I got to his age and thought "oh my God, I'm going to be as old as he was when he had me" and then I sort of passed that, so yeah that was a factor ... I think this goes back to behaviour rather than actual age; I think my father acted his age and also he drank and smoked a lot so that tends to age people. So I think that at my age he would have looked and acted older than I do. (Guy, 47, D, child aged 4 months)

Jason makes a similar point about how he manages to retain a younger mindset than his own (older) father had done during his childhood. 
We're a lot younger I would say in mindset, like, he was very much of his age and they grew up and then became very, once they got married they then were quite happy to settle into staying at home, pipe and slipper type thing... when I was growing up sit and listening to music my mum and dad would be happily listening to radio 2 and they would be about the same age as me, where we still listen, and I know it's really simple but we still listen to radio 1, and like know, the kids know all the latest songs and so do we to an extent. (Jason, 40, A, children aged 8 and 5)

Drawing on these comparisons with previous generations was one way in which men like Jason and Guy were able to highlight the positive aspects of their own position. However, both continued to describe anxieties about the physical aspects of ageing, suggesting that whilst chronological age might not equate with subjective age (Bytheway, 2005) it remained a powerful concept for structuring experience.

The issue of maintaining physical ability was increasingly raised as both fathers and children got older, particularly in relation to sons. Research by Daniels and Weingarten (1983) found that advanced paternal age was reported as problematic by sons but not daughters, as sons felt their own fathers had been 'too old' to be the kind of father they wished they had. In contrast, mothers' age was not seen by any participants as a handicap in performing their 'motherly duties'. The authors speculate that as fathers and sons have traditionally been expected to do 'active manly things' together, an older father may be seen as a handicap. In contrast, relationships with daughters were seen to be more passive and require less physical endurance, therefore were less problematic for older fathers. This perception was remarked 
upon by a number of men in our own study and led to a preference for girls among some older fathers; the highest rate of girl preference across all age groups in the sample.

I think part of it [girl preference] might be to do with the fact that if I had a boy then I would sort of feel an obligation to play football and um get involved with boy-ish things, and there my age might have started to become a factor. I don't know if they still do this but I know when I was a kid at school they'd have fathers against children cricket matches and stuff (laughs) and I sort of, by the time they get to that age - sort of 10/12 - then I'd be in my late 50s by that stage so I don't know how (laughs) good I'd be in a cricket team. (Guy, 47, D, 4 month old child)

I think certainly my children are keeping me young ... probably I'm lucky I don't have boys because I'd have to start going to the gym (amusement) just to keep up. (Kenny, 49, A, children aged 8 and 6)

This continuing association of boys with activity and girls with passivity suggests underlying essentialist conceptions of gender, to an extent, continue to inform men's views about parenting. Whilst this was particularly evident during pregnancy and the early stages of fatherhood, it became somewhat less marked with older children when daughters were also found to be active or where sons did not enjoy physical activities. However, activity with sons continued to be seen as an important aspect of good fatherhood, which may be why concerns about ageing were more pronounced amongst fathers of boys. Terry was one of the most vocal in expressing concerns about age-related limitations to being physically active with his son. 
I do regret being a bit old for him. If I was a bit younger I would be more active and out there doing more adventurous things with him but, my knees hurt and, you know, things are hurting and falling off and things, I'm not quite so physically active with him as I would like to be. We recently had his cousins up, some of which are teenagers and they were just tearing around playing football all afternoon and I can’t keep up, and I regret being a bit old for that. (Terry, 46, A, eight year old child)

As Terry's transition to fatherhood had been delayed by almost a decade due to fertility difficulties, it may be that he was less inclined to be positive about the timing of this transition than those who had chosen to become fathers later in life. Terry's interviews were dominated by talk about health and illness, reflected in the concerns he held for his son.

I don't want him to grow up to be the school wheeze if you like. I want him to go out and play football and rugby and cricket and lark around in the playground with his mates. Not to be the kid who is excused to do PE because of you know the asthma.

This highlights the way in which physical activity appears to be emphasised between fathers and sons, with limitations to this proving particularly problematic in terms of masculinity. However, although often negative about this aspect of their fathering experience, older fathers sought different ways to highlight their parenting competence and emphasise the benefits of a later transition to parenthood. For example, some commented on their longer 
careers and greater occupational and financial stability, highlighting a different aspect of masculine father identity in relation to economic provision.

\section{Conclusions}

This paper lends support to the assertion that anxiety about ageing occurs in young and middle-age as people assess their progress through the life course with reference to the concept of age. Indeed, the data also appear to confirm the contention that we are now more acutely aware of chronological age than ever before (Brannen, 2002). Whilst the focus on change through time inherent in qualitative longitudinal research may have heightened the prominence of talk about ageing, the extent to which it emerged across the sample suggests that it is a relevant issue for fathers and not simply a product of the research methodology. Throughout the sample men held negative perceptions of old age and expressed anxiety about ageing, predominantly in terms of declining ability 'to do'. Although some men, such as Keith, made explicit efforts to improve physical health, and despite wider trends towards increasingly longevity, the association between increasing chronological age and physical decline appears to be a powerful one for many of the men in the study and continues to imbue the ageing process with anxiety. One of the main ways in which this anxiety was expressed was in relation to being an older father, associated with reduced physical fitness through terms such as 'knackered' 'sweaty' and 'wheezy'. It is striking that these concerns about ageing emerged across the sample group and not just amongst the oldest fathers, indicating how pervasive such anxiety can be. These anxieties may be linked with the way men's experiences appeared to reflect a linear perception of time, where chronological age is a marker of life course progression, albeit one which is socially weighted with a concentration of events in the earlier stages and associations of loss and decline in the latter. This underlines the way in which age continues to be an important identity marker (Jagger, 2005) 
which has a significant impact on the experience and expectations of fatherhood. Consequently, future research needs to address the impact these perceptions of ageing have on both fertility timing decisions and the lived experience of fatherhood.

The concerns about ageing presented in this paper focussed predominantly on the men's ability to be physically active with their child, particularly through sport. Being older or unfit in this context was seen as a potential embarrassment to children and threatened the mutual sense of pride that most fathers anticipated in relationships with their offspring. It could be argued that this reflects a relatively modern aspect of fatherhood of the father as playmate and friend. However, this increasing prominence of physical activity as an important aspect of fatherhood is perhaps unsurprising in light of arguments outlined in the introduction which suggest the double standard of ageing is becoming fragmented as growing older represents a move away from hegemonic masculinity, based on the lives and bodies of younger men. This is evident in the way the fathers made reference to other men; in the fathers' race at sports day or as the 'veteran' of a sports team, indicating continuing associations of masculinity, sport, and bodily performance (Robertson, 2003; Connell, 2005). However, those who felt unable to meet what they saw as adequate standards of physical activity often emphasised other aspects of masculine identity which positioned them as good fathers. For example, older fathers were more likely to highlight their ability to provide financially for the child as they had had longer to establish their careers.

The importance of remaining active appears to be linked to men's memories of their own fathers; wanting to enjoy similar activities, or wanting their children to avoid the embarrassment or frustration they had felt at their own father's inactivity and physical form. Consequently, chronological age acted as a particularly important benchmark for men who 
had had older fathers, prompting some to become a father at an earlier age. Inflected with these memories, chronological age and physical activity were identified as significant for men in decisions about the timing of fatherhood. In light of these negative perceptions of ageing in the context of fatherhood, why are increasing numbers of men delaying parenthood until later in life? For many men in the study delay was a result of circumstances rather than choice; whilst physical fitness is important, it does not appear to outweigh the need to have a stable relationship, financial and employment situation, all of which can take time to establish. However, for those men who have these pre-requisites in place, the looming 'spectre' of becoming a father who was unfit or inactive due to age was a significant impetus in some men's decision not to delay childbearing any longer. This is not an issue which has been identified by existing research on fertility decision-making - a literature which pays relatively little attention to men (Jamieson et al., 2010) - but the centrality of physical fitness in these men's accounts would suggest it is an important area to be accounted for in future research. As most men made the transition to parenthood later than their own parents had done, memories of their own fathers' age-related physical inactivity were not widespread. However, the increasing trend towards delayed parenthood suggests that this may become a more pressing issue for future generations, as relationships between older parents and their adult children are an increasingly important element of intergenerational interaction (Grundy, 2005), and therefore warrants further consideration.

It is striking that concerns about ageing were mentioned more frequently by men who had sons than those with daughters, as girls were deemed passive and less physically demanding. This was further supported by the oldest fathers being the only group in the sample more likely to express a preference for daughters, apparently in relation to concerns that they would be unable to 'keep up' with sons. In contrast, the youngest fathers in the sample were 
most likely to express a preference for sons, highlighting their energy for physical activity as one of the few advantages they had in making an early transition to fatherhood. Thus, the data appear to suggest that ageing has particular implications for masculinity in relation to parenthood, which is perhaps unsurprising given that many boys grow up in a culture which emphasises physical activity and independence (Doucet, 2009). However, research which considers older children and adolescents' views of parental age and the impact this has on the father-child relationship would be required to further substantiate these claims.

\section{$\underline{\text { Acknowledgements }}$}

I would like to acknowledge and thank Professor Karen Henwood, Principal Investigator of the Men as Fathers project. I am also grateful to the reviewers for their helpful comments. Some of the data presented in this paper are drawn from projects supported by ESRC grants numbers R02225016 and RES-347-25-0003.

\section{$\underline{\text { References }}$}

Arber S, Davidson K, and Ginn J Changing Approaches to Gender and Later Life. In Arber S, Davidson K, Ginn J (Eds) (2003) Gender and Ageing: Changing Roles and Relationships. Maidenhead: Open University Press. 1-14.

Bell K, and McNaughton D, (2007) Feminism and the Invisible Fat Man. Body and Society. 13(1): 107-131

Brannen J, (2002) Lives and time: a sociological journey. (Professorial Lecture) Institute of Education: University of London. 
Bytheway B, (2005) Age-identities and the celebration of birthdays. Ageing and Society. 25(4): 463-77.

Calasanti T, and King N (2005) Firming the Floppy Penis: Age, class and gender relations in the lives of old men. Men and Masculinities. 8(1): 3-23.

Coltart C, and Henwood K (2012) On paternal subjectivity: a qualitative longitudinal and psychosocial case analysis of men's classed positions and transitions to first-time fatherhood. Qualitative Research. 12(1): 35-52

Comeau TD, and Kemp CL (2007) Intersections of age and masculinities in the information technology industry. Ageing and Society. 27(2): 215-232.

Connell RW (2005) Masculinities: Second Edition. Cambridge: Polity Press.

Daniels P, and Weingarten K (1983) Sooner or Later: The Timing of Parenthood in Adult Lives. New York: W.W. Norton.

Doucet A (2006) 'Estrogen-filled worlds': fathers as primary caregivers and embodiment. The Sociological Review. 54(4): 696-716.

Docuet A (2009) Dad and Baby in the First Year: Gendered Responsibilities and Embodiment. The Annals of the American Academy of Political and Social Sciences. 624(1): 78-98. 
Eisler R, and Ragsdale K (1992) Masculine Gender Role and Midlife Transition in men. In Van Hasselt VB, and Hersen M (Eds) Handbook of Social Development. NY: Academic Press. 455-470.

Elchardus M, and Smits W (2006) The Persistence of the Standardized Life Cycle. Time and Society. 15(2/3): 303-326.

Elliott J, Holland J, and Thomson R (2008) Longitudinal and Panel Studies. In Alasuutari P, Bickman L, and Brannen J (Eds) Handbook of Social Research Methods. London: Sage. 228248.

Fleming AA, (1999) Older men in contemporary discourses on ageing: absent bodies and invisible lives. Nursing Inquiry. 6(1): 3-8.

Gill R, Henwood K, and McLean C (2005) Body Projects and the Regulation of Normative Masculinity. Body and Society. 11(1): 37-62

Grundy E, (2005) Reciprocity in relationships: socio-economic and health influences on intergenerational exchanges between Third Age parents and their adult children in Great Britain. The British Journal of Sociology. 56(2): 233-255.

Gulette MM, (1997) Declining to Decline: Cultural Combat and the Politics of Midlife. Charlottesville, VA: University Press of Virginia. 
Halliwell E, and Dittmar H (2003) A Qualitative Investigation of Women's and Men's Body Image Concerns and Their Attitudes Toward Aging. Sex Roles. 49(11/12): 675-684.

Hamand J (1994) Father Over Forty: Becoming an Older Father. London: Optima.

Hearn J (1995) Imaging the Aging of Men. In Featherstone D, and Wernick A (Eds) Images of Aging. London: Routledge. 97-115.

Henwood K, Gill R, and Mclean C, (2002) The Changing Man. The Psychologist. 15(4): 182186.

Henwood, K. Shirani, F. and Coltart, C. (2010) Fathers and financial risk-taking during the economic downturn: Insights from a QLL study of men's identities-in-the-making. Contemporary Social Science (formerly $21^{\text {st }}$ Century Society). 5 (2) 137-147

Hepworth, M. (1995). Positive aging, what is the message? In Bunton,R. Nettelton,S. and Burrows, R. (Eds.), The sociology of health promotion. New York: Routledge.

Hummert ML, Gartska TA, Shaner JL, and Strahm S (1994) Stereotypes of the Elderly Held by Young, Middle-Aged and Elderly Adults. Journal of Gerontology. 49(5): 240-249.

Jamieson L, Backett-Milburn K, Simpson R, and Wasoff F (2010) Fertility and social change: the neglected contribution of men's approaches to becoming partners and parents. The Sociological Review. 58(3): 463-485. 
Jagger E (2005) Is Thirty the New Sixty? Dating, Age and Gender in a Postmodern, Consumer Society. Sociology. 39(1): 89-106.

Lamb M (Ed) (2010) The Role of the Father in Child Development: Fifth Edition. Hoboken, NJ: John Wiley and Sons.

Mac an Ghaill M, and Haywood C (2007) Gender, Culture and Society: Contemporary Masculinities and Femininities. Basingstoke: Palgrave Macmillan.

Marshall BL, and Katz S (2002) Forever Functional: Sexual Fitness and the Ageing Male Body. Body and Society. 8(4): 43-70.

ONS (2009) Birth Statistics 2008 Series FM1 No. 37. Office of National Statistics. Accessed http://www.statistics.gov.uk/downloads/theme_population/FM1-37/FM1_37_2008.pdf

Parke R (1996) Fatherhood. Cambridge, MA: Harvard University Press.

Robertson S (2003) 'If I let a goal in, I'll get beat up': contradictions in masculinity, sport and health. Health Education Research. 18(6): 706-716.

Shirani F (2010) Researcher Change and Continuity in a Qualitative Longitudinal Study: The Impact of Personal Characteristics. In Shirani F and Weller S (Eds) Conducting Qualitative Longitudinal Research: Fieldwork Experiences. Timescapes Working Paper Series No. 2.

Shirani F, Henwood K and Coltart C (2012) Meeting the challenges of intensive parenting culture: gender, risk management and the moral parent. Sociology. 46(1) 25-40. 
Shirani F and Henwood K (2011) Continuity and Change in a qualitative longitudinal study of fatherhood: Relevance without responsibility. International Journal of Social Research Methodology. 14 (1) pp17-29.

Spector-Mersel G (2006) Never-aging Stories: Western Hegemonic Masculinity Scripts. Journal of Gender Studies. 15(1): 67-82.

Thompson Jr. EH (2006) Images of Old Men's Masculinity: Still a Man? Sex Roles. 55(9/10): 633-648.

Vickerstaff S (2006) Life Course, Youth, and Old Age. In Taylor-Gooby P, and Zinn J (Eds) Risk in Social Science. Oxford: Oxford University Press. 180-201.

Wandel M, and Roos G, (2002) Age perceptions and physical activity among middle-aged men in three occupational groups. Social Science and Medicine. 62(12): 3024-3034.

\footnotetext{
i These figures reflect situations at the birth of first child, circumstances varied across the time period of the study
}

\section{Biography}

Fiona Shirani is a Research Associate at Cardiff University, School of Social Sciences. Her research interests include time, families and the impact of life course transitions. She is currently working on the qualitative longitudinal project 'Energy Biographies'. 